different experiences my foundation doctor colleagues (and also undergraduates on their attachments) have had depending on whether they are working in general adult or old age psychiatry.

That recruitment into psychiatry is a problem is not news and the Royal College of Psychiatrists has launched a 5-year plan to increase applicants to psychiatry. ${ }^{2}$ The reasons for this have been argued as being multifactorial, ${ }^{3}$ however, a large part appears to be the view that psychiatry is an 'inferior' specialty, that psychiatrists become 'deskilled' in their medical knowledge and that, with New Ways of Working, consultant psychiatrists may feel disempowered, with less control of their workload leading to greater stress and reduced job satisfaction. There is also a feeling of psychiatry being somewhat separate from the other medical specialties. Most mental health services are run out of separate hospitals, and indeed separate trusts, and medical students and other doctors rarely see psychiatrists in ward rounds.

The viewpoint of those who have done a foundation job in old age psychiatry, however, appears to be somewhat different. Admittedly, my impression has been formed only through informal discussions about a subspecialty to which I am already committed. As the medic in the team, foundation doctors experience the more complex patients and are required to keep their skills up to date regarding the medical needs of patients, either as in-patients, out-patients or in liaison services. They are often required to liaise with teams based in the general hospital on the care of patients, who, by the nature of the specialty, often have a variety of health problems, particularly neurological, given the overlap in presentation. They have the opportunity to be involved in liaison work and therefore have face-to-face contact with colleagues in other specialties, thus preventing the feeling of separateness and isolation from other disciplines. Although emphasis is still on multidisciplinary team working, each member of the team, including the consultant, has individual roles depending on their skills and job title. They therefore see the consultant of the team being treated with the realisation that their skills are better used for diagnosis, treatment, clinical decision-making and leadership of the team while drawing on the skills of other professionals.

Barras \& Harris ${ }^{4}$ have commented that if attrition from psychiatry is to be minimised, issues such as how psychiatric trainees integrate with other medical specialties, and how the role of doctors in the specialty is perceived need to be addressed, and I would certainly agree. What retained me in working in psychiatry at a time when New Ways of Working and exam pressures were resulting in demoralisation, was my experience in old age psychiatry.

1 Kelley TA, Brown J, Carney S. Foundation Programme psychiatry placement and doctors' decision to pursue a career in psychiatry. Psychiatrist 2013; 37: 30-2

2 Jaques H. Royal College launches five year plan to increase applicants to psychiatry. BMJ Careers 2012; 27 March (http://careers.bmj.com/ careers/advice/view-article.html?id=20007042).

3 Sekhri R, Sibbett R. Recruitment in psychiatry: a complex and multifactorial problem. Psychiatrist 2012; 36: 118-9.

4 Barras C, Harris J. Psychiatry recruited you, but will it retain you? Survey of trainees' opinions. Psychiatrist 2012; 36: 71-7.

Sophia A. Bennett, CT3 community old age psychiatry, Bowes Lyon Unit, Lanchester Road Hospital, Durham, UK, email: sophia.bennett@nhs.net

doi: $10.1192 / \mathrm{pb} .37 .4 .148 \mathrm{~b}$

\section{Perhaps a different viewpoint is needed?}

Kelley et $a l^{1}$ raise an interesting point with regard to Foundation Programme placements and subsequent careers in psychiatry, and I applaud their aim. What they look at is whether having experience of psychiatry in the foundation years results in a placement in psychiatry at CT1 level - I would suggest this is not quite the same as influencing a trainee's decision to apply. As suggested in the discussion, I would imagine those keen on a future career in psychiatry are more likely to opt for rotations which contain psychiatry, but how many of these people are dissuaded from applying by a negative experience? Furthermore, how many people go through the application process for a CT post in psychiatry ultimately to be unsuccessful for reasons aside from not having had a taster/ FY post? Perhaps an alternative way of approaching this situation would be to survey the career aspirations of newly qualified FY1s, making note of the FY2 rotations they go through and ultimately which specialties they apply for - in addition to which one they subsequently choose. This method would look for an association between FY2 posts and applications to psychiatry, not just those who are awarded a training post.

1 Kelley TA, Brown J, Carney S. Foundation Programme psychiatry placement and doctors' decision to pursue a career in psychiatry. Psychiatrist 2013; 37: 30-2.

Matthew J. Cordiner, CT3 Psychiatry, Ailsa Hospital, Ayr, UK, email: matthewcordiner@nhs.net

doi: $10.1192 / p b .37 .4 .149$ 